Research Paper

\title{
Enterotoxigenic and non-enterotoxigenic Bacteroides fragilis from fecal microbiota of children
}

\author{
Aline Ignacio, Miriam Rodriguez Fernandes, \\ Mario Julio Avila-Campos, Viviane Nakano \\ Departamento de Microbiologia, Instituto de Ciências Biomédicas, Universidade de São Paulo, \\ São Paulo, SP, Brazil.
}

Submitted: August 26, 2014; Approved: May 19, 2015.

\begin{abstract}
Enterotoxigenic Bacteroides fragilis (ETBF) is an important part of the human and animal intestinal microbiota and is commonly associated with diarrhea. ETBF strains produce an enterotoxin encoded by the $b f t$ gene located in the $B$. fragilis pathogenicity island (BfPAI). Non-enterotoxigenic $B$. fragilis (NTBF) strains lack the BfPAI and usually show two different genetic patterns, II and III, based on the absence or presence of a BfPAI-flanking region, respectively. The incidence of ETBF and NTBF strains in fecal samples isolated from children without acute diarrhea or any other intestinal disorders was determined. All 84 fecal samples evaluated were B. fragilis-positive by PCR, four of them harbored the $b f t$ gene, 27 contained the NTBF pattern III DNA sequence, and 52 were considered to be NTBF pattern II samples. One sample was positive for both ETBF and NTBF pattern III DNA sequences. All $19 \mathrm{~B}$. fragilis strains isolated by the culture method were $b f t$-negative, 9 belonged to pattern III and 10 to pattern II. We present an updated overview of the ETBF and NTBF incidence in the fecal microbiota of children from Sao Paulo City, Brazil.
\end{abstract}

Key words: Bacteroides fragilis, children, ETBF, NTBF.

\section{INTRODUCTION}

The intestinal tract is a complex ecosystem and the relationships between the microbiota and the host can result in symbiotic and/or pathogenic outcomes (Hooper and Gordon, 2001). The colon is known to contain up to $10^{13}$ bacteria/g of feces and the bacterial community predominantly belong to the Firmicutes and Bacteroidetes phyla. Bacteroides species comprise about $30 \%$ of the total cultivable microbiota, and among them Bacteroides fragilis is an important part of the human and animal microbiota and one of the most studied intestinal species (Karlsoon et al., 2011; Wick and Sears, 2010).

This microorganism has been associated with extra-intestinal infections, such as intra-abdominal, lung and brain abscesses (Tzianabos et al., 1994). Some strains are able to produce an enterotoxin (fragilysin or BFT) which is encoded by the $b f t$ gene located in a $6-\mathrm{kb}$ pathogenicity island (BfPAI). These strains are called enterotoxigenic $B$. fragilis $(\mathrm{ETBF}$, pattern I) strains and are associated with acute diarrhea in humans and animals. Non-enterotoxigenic $B$. fragilis (NTBF) strains are also found in intestines of healthy individuals. They lack the BfPAI and represent two genetic patterns, pattern II (without a 12-kb BfPAI flanking region) and pattern III (with the flanking region) (Franco et al., 1999).

Studies in Bangladesh, Turkey and Vietnam showed a consistent association of ETBF with human diarrhea in children under five years of age (Durmaz et al., 2005; Nguyen et al., 2005; Sack et al., 1994). Pantosti et al. (1997) reported a high rate of ETBF carriage among healthy subjects, suggesting that ETBF rates in the human intestinal microbiota may vary widely depending on geographical areas.

Diarrhea is one of the most common diseases in humans and is considered a serious risk to infants in developing countries. In Brazil, the ETBF rate is low ranging from 1.5 to 3\% (Antunes et al., 2004; Bressane et al., 2001;

Send correspondence to V. Nakano. Departamento de Microbiologia, Instituto de Ciências Biomédicas, Universidade de São Paulo, Av. Prof. Lineu Prestes 1374, 05508-900, São Paulo, SP, Brazil. E-mail: vivinkn@usp.br. 
Kryzanowsky et al., 2003). However, Miranda et al. (2008) showed an increase in the incidence of ETBF and NTBF, particularly NTBF pattern III strains. Merino et al. (2011) confirmed the presence of ETBF in children without diarrhea, suggesting that children could be a reservoir for these strains however, the presence of NTBF patterns II and III was not evaluated.

The presence of BfPAI flanking region observed in NTBF pattern III strains may indicate that the toxin gene can be transferred horizontally from ETBF to NTBFstrains (Franco et al., 1999). This shows the need of evaluating the distribution of ETBF and NTBF strains in the intestinal microbiota of healthy children as eventual reservoirs of these microorganisms. In this study, the distribution and prevalence of $B$. fragilis, as well as the incidence of ETBF and NTBF strains in healthy children, were determined.

\section{Materials and Methods}

\section{Samples}

Normal fecal samples were collected from 84 children ( 46 boys and 38 girls) between the ages of 3 and 12 years old who had no signs of acute diarrhea or other intestinal disorders. The children were private and municipal schools students from Sao Paulo City, SP, Brazil. No child had undergone antibiotic therapy in at least 3 months prior to the sample collection. This study was approved by the Ethic Committee of the Institute of Biomedical Sciences of the University of Sao Paulo (No. 1043/CEP). The fecal samples were directly plated onto Bacteroides Bile Esculin (BBE) agar medium and incubated in anaerobiosis at $37{ }^{\circ} \mathrm{C}$ for 4 days. Characteristic colonies from each plate were subcultured on Brain Heart Infusion (BHI) agar supplemented with blood.

\section{PCR analysis}

Bacterial DNA from the 84 feces samples and 192 bacterial isolates was obtained using, respectively, the commercial QIAmp DNA Stool Mini Kit and QIAmp DNA Mini Kit (QIAGEN), according to the manufacturer's instructions. DNA was stored at $-80^{\circ} \mathrm{C}$ until use.

The presence of $B$. fragilis in the fecal samples was detected by PCR amplification with $16 \mathrm{~S}$ rRNA primers. DNA from the bacterial isolates was amplified with 16S-23S rRNA primers. All DNA samples positive for $B$. fragilis were screened for the presence of ETBF and/or NTBF sequences. The oligonucleotide pairs and amplification conditions used are described in Table 1.

All PCR assays were performed as follows: $1 \mathrm{X}$ PCR buffer, $50 \mathrm{mM} \mathrm{MgCl}_{2}, 0.2 \mathrm{mM}$ dNTP mix, $0.4 \mathrm{mM}$ each primer, $0.5 \mathrm{U}$ of Platinum Taq polymerase (Invitrogen), and $1 \mathrm{ng}$ of DNA. PCR products were analyzed by $1 \%$ agarose gel electrophoresis, stained with $0.5 \mu \mathrm{g} / \mathrm{mL}$ of ethidium bromide and photographed under UV light.
B. fragilis ATCC 43858 (ETBF pattern I, $b f t^{+}$) and ATCC 25285 (NTBF pattern III, $b f t$ ) were used, respectively, as positive and negative controls. The other strains used as controls were: B. thetaiotaomicron ATCC 29741, B. vulgatus ATCC 8482, B. caccae ATCC 43185, B. ovatus ATCC 8483, B. eggerthii ATCC 27754, B. uniformis ATCC 8492, B. stercoris ATCC 43183, Parabacteroides distasonis ATCC 8503, and P. merdae ATCC 43184.

\section{Statistical analysis}

The chi-square test was used to analyze the data on the presence of ETBF and NTBF strains, obtained by PCR and the culture method. The significance level was set at $5 \%$ using the BioEstat 2009 version 5.3.5.

\section{Results}

A total of 192 isolates were obtained from 84 children by culture method. Among those, 19 strains isolated from 8 $(9.5 \%)$ children were identified as B. fragilis by $16 \mathrm{~S}-23 \mathrm{~S}$ rRNA PCR. None harbored the $b f t$ gene. Nine (47.3\%) out of the 19 B. fragilis strains, isolated from 3 children, contained a 1.6-kb amplicon and therefore belonged to NTBF pattern III. The remaining $10(52.7 \%)$ B. fragilis strains obtained from 5 children did not show DNA amplification and were considered belonging to NTBF pattern II (Table 2).

PCR analysis of the DNA isolated from the fecal samples showed that all 84 samples were positive for B. fragilis and four $(4.7 \%)$ out of the 84 children were $b f t$-positive. Twenty seven (32.1\%) out of the 84 samples produced a 1.6-kb amplicon, thus belonging to NTBF pattern III, while $52(61.9 \%)$ samples did not generate any DNA amplification products and thus were considered NTBF pattern II samples. In one fecal sample (1.2\%), the presence of both ETBF and NTBF pattern III DNA sequences was observed. Moreover, statistical analysis did not show significant differences between the bacterial isolates and fecal samples in regards to the presence of NTBF pattern II $(p=0.456)$ and pattern III $(\mathrm{p}=0.209)$ (Table 2).

\section{Discussion}

The impact of the resident microbiota on human health has been extensively discussed, and studies have suggested that alterations of the intestinal ecology might be associated with inflammatory bowel diseases, diabetes or obesity (Musso et al., 2011; Shen et al., 2012).

Microbial culture is considered the gold standard for detection of bacteria, but requires a high number of viable cells. Bacterial characterization by different methods, including DNA analysis, has also been used to elucidate microbiota-host interactions. In this study, 19 B. fragilis strains isolated from feces did not harbor the $b f t$ gene. Since ETBF strains are associated with acute diarrhea processes, their presence was not expected in children without diarrhea. Determination of the genetic patterns (I, II or III) was 
Table 1 - Oligonucleotides and PCR conditions used to detect toxigenic and non-toxigenic B. fragilis.

\begin{tabular}{|c|c|c|c|c|}
\hline \multirow[t]{2}{*}{ Genes } & Oligonucleotides & Amplification & Size & \multirow[t]{2}{*}{ References } \\
\hline & $5^{\prime} \rightarrow 3^{\prime}$ & Conditions & (bp) & \\
\hline & & 35 cycles & & \\
\hline \multirow[t]{2}{*}{ B. fragilis } & F: GTACACACCGCCCGT & $94^{\circ} \mathrm{C} \times 30 \mathrm{~s}$ & 420 & (9) \\
\hline & R: GCTAATCCCCCAATCATAC & $62{ }^{\circ} \mathrm{C} \times 30 \mathrm{~s}$ & & \\
\hline$(16-23 \text { rRNA })^{*}$ & & $72{ }^{\circ} \mathrm{C} \times 30 \mathrm{~s}$ & & \\
\hline \multirow{4}{*}{$\begin{array}{l}\text { B. fragilis } \\
(16 \mathrm{~S} \text { rRNA })^{* *}\end{array}$} & F: TCRGGAAGAAAGCTTGCT & 35 cycles & 162 & $(18)$ \\
\hline & R: CATCCTTTACCGGAATCCT & $94^{\circ} \mathrm{C} \times 30 \mathrm{~s}$ & & \\
\hline & & $56^{\circ} \mathrm{C} \times 60 \mathrm{~s}$ & & \\
\hline & & $72{ }^{\circ} \mathrm{C} \times 60 \mathrm{~s}$ & & \\
\hline \multirow[t]{4}{*}{$b f t$ gene } & F: GACGGTATGTGATTTGTCTGAGAGA & 35 cycles & 294 & (14) \\
\hline & R: ATCCCTAAGATTTTATCCCAAGTA & $94^{\circ} \mathrm{C} \times 30 \mathrm{~s}$ & & \\
\hline & & $52^{\circ} \mathrm{C} \times 60 \mathrm{~s}$ & & \\
\hline & & $72^{\circ} \mathrm{C} \times 60 \mathrm{~s}$ & & \\
\hline \multirow[t]{4}{*}{$\mathrm{NTBF}^{* * *}$ Patterns } & F: TTCAACCTGATCGATCCGGAAGATCCG & 29 cycles & 1600 (pattern III) None (pattern II) & $(5)$ \\
\hline & R: GCTGGTAGACTACCTGAGTAAGGAGTC & $94^{\circ} \mathrm{C} \times 60 \mathrm{~s}$ & & \\
\hline & & $66^{\circ} \mathrm{C} \times 2 \mathrm{~min}$ & & \\
\hline & & $72{ }^{\circ} \mathrm{C} \times 60 \mathrm{~s}$ & & \\
\hline
\end{tabular}

*Primer used to identify B. fragilis from bacterial isolates.

${ }^{* *}$ Primer used to identify B. fragilis from fecal samples; Degenerate primer R=A/G.

${ }^{* * * *}$ NTBF: Non-enterotoxigenic Bacteroides fragilis.

Table 2 - Presence of enterotoxigenic and non-enterotoxigenic Bacteroides fragilis in 19 bacterial isolates and 84 fecal samples.

\begin{tabular}{|c|c|c|c|c|c|}
\hline \multirow[t]{2}{*}{ B. fragilis } & \multicolumn{2}{|c|}{ Bacterial isolates } & \multicolumn{2}{|c|}{ Fecal samples } & \multirow[t]{2}{*}{$p^{\S}$} \\
\hline & $\mathrm{n}$ & $\%$ & $\mathrm{n}$ & $\%$ & \\
\hline $\mathrm{ETBF}^{*}$ & 0 & 0 & 4 & 4.7 & $-^{a}$ \\
\hline \multicolumn{6}{|l|}{ Pattern I } \\
\hline $\mathrm{NTBF}^{* *}$ & 10 & 52.6 & 52 & 61.9 & 0.456 \\
\hline \multicolumn{6}{|l|}{ Pattern II } \\
\hline NTBF & 9 & 47.4 & 27 & 32.1 & 0.209 \\
\hline \multicolumn{6}{|l|}{ Pattern III } \\
\hline ETBF + NTBF III & 0 & 0 & 1 & 1.2 & $-^{\mathrm{a}}$ \\
\hline
\end{tabular}

${ }^{\S}$ Significance level for chi-square test. $\mathrm{p}<0.05$.

${ }^{a}$ Without sufficient sample to perform the chi-square test.

*ETBF: Enterotoxigenic Bacteroides fragilis.

${ }^{* *}$ NTBF: Non-enterotoxigenic Bacteroides fragilis.

performed in this study by using DNA obtained from the bacterial isolates and feces. To achieve better accuracy and specificity in the NTBF pattern II determination, a $16 \mathrm{~S}$ rRNA-specific primer pair to B. fragilis was used to evaluate all DNA samples.

Studies have shown the presence of ETBF in $2 \%$ to $3 \%$ of Brazilian children from 1 month to 12 years old without diarrhea (Bressane et al., 2001; Kryzanowsky et al.,
2003). In our study, four (4.7\%) out of the 84 samples harbored the $b f t$ gene and they originated from children older than 5 years of age, thus showing a slight increase of the ETBF rate, compared to the previous studies. Merino et al. (2011) showed no statistically significant difference in the incidence and number of ETBF strains detected in fecal samples from children with and without diarrhea. 
B. fragilis strains harboring the bft gene have been associated with inflammatory bowel disease and colorectal cancer, and their phenotypic and genotypic features could be used to evaluate the involvement of these strains in various human disorders (Basset et al., 2004; Prindiville et al., 2000; Toprak et al., 2006).

The $b f t$ gene is located in the 6-kb BfPAI flanked by a $12-\mathrm{kb}$ region. Nucleotide analysis of the flanking region suggests that the BfPAI is a mobile genetic element and could be transferred from ETBF to NTBF strains. Since, the BfPAI or its flanking regions can be self-mobilized, and the presence of the 12-kb region observed in NTBF pattern III strains is suggestive of this event (Franco et al., 1999), comprehensive evaluation of $B$. fragilis strains isolated from children without diarrhea is justified.

A high prevalence of NTBF pattern III strains has been observed in different geographic areas, such as Bangladesh and Korea (Franco et al., 1999). In this study, 9 (47.4\%) out of 19 NTBF strains belonged to pattern III and $10(52.6 \%)$ belonged to pattern II. Our results also showed that $27(32.1 \%)$ fecal samples contained NTBF pattern III DNA sequence, and 52 (61.9\%) samples contained NTBF pattern II DNA sequence. One sample contained both ETBF and NTBF pattern III DNA sequence and should be further analyzed. There were differences in the prevalence of patterns II and III between the bacterial and fecal samples (Table 2). This could be explained by a lower number of samples positive for $B$. fragilis ( 8 samples) obtained by the culture-based technique. Although the NTBF pattern II was prevalent in both bacterial and fecal samples, our results showed a low rate of ETBF.

In a longitudinal study conducted during a period of one year, Zitomersky et al. (2011) observed the presence of ETBF in 6 out of 15 healthy individuals, of which 3 harbored only ETBF, while 2 harbored ETBF and NTBF during this period. The authors suggested that an individual can harbor more than one strain at the same time and toxigenic strains can persist in the intestinal ecosystem without causing acute damage to their host.

In conclusion, our results showed a low incidence of ETBF in the intestinal tract of children without diarrhea. However, a relatively high incidence of NTBF strains, especially those belonging to pattern III, suggests that further investigations are needed, specially due to the possibility that NTBF strains may become ETBF by acquiring the BfPAI. In addition, longitudinal studies must be conducted to investigate the persistence of ETBF strains in healthy subjects and their association with clinical conditions such as diarrhea, colitis and colorectal cancer.

\section{Acknowledgments}

Authors thank Ms. Marcia Harumi Fukugaiti for her technical support. The ATCC strains were kindly donated by Dr. Sydney M. Finegold from Veterans Affairs, West Los Angeles Medical Center, Los Angeles, CA, USA. Dur- ing the course of this work $\mathrm{AI}$ and $\mathrm{VN}$ were supported by FAPESP fellowship (2012/10659-7 and 2009/03792-0, respectively). This study was supported by Fundação de Amparo a Pesquisa do Estado de Sao Paulo (FAPESP Grant No. 2008/57330-4).

\section{References}

Antunes ENF, Ferreira EO, Falcão LS et al. (2004) Non-toxigenic pattern II and III Bacteroides fragilis strains: coexistence in the same host. Res Microbiol 155:522-524.

Basset C, Holton J, Bazeos A et al. (2004) Are Helicobacter species and enterotoxigenic Bacteroides fragilis involved in inflammatory bowel disease? Dig Dis Sci 49:1425-1432.

Bressane MA, Durigon LE, Avila-Campos MJ (2001) Prevalence of the Bacteroides fragilis group and enterotoxigenic Bacteroides fragilis in immunodeficient children. Anaerobe 7:277-281.

Durmaz B, Dalgalar M, Durmaz R (2005) Prevalence of enterotoxigenic Bacteroides fragilis in patients with diarrhea: a controlled study. Anaerobe 11:318-321.

Franco AA, Cheng RK, Chung GT et al. (1999) Molecular evolution of the pathogenicity island of enterotoxigenic Bacteroides fragilis strains. J Bacteriol 181:6623-6633.

Hooper LV, Gordon JI (2001) Commensal Host-Bacterial Relationships in the gut. Science 292:1115-1117.

Karlsson FH, Ussery DW, Nielsen J et al. (2011) A closer look at Bacteroides: phylogenetic relationship and genomic implications of a life in the human gut. Microb Ecol 61:473-485.

Kryzanowsky F, Avila-Campos MJ (2003) Detection of nonenterotoxigenic and enterotoxigenic Bacteroides fragilis in stool samples from children in São Paulo, Brazil. Rev Inst Med Trop S Paulo 45:225-227.

Liu C, Song Y, McTeague M et al. (2003) Rapid identification of the species of the Bacteroides fragilis group by multiplex PCR assays using group- and species-specific primers. FEMS Microbiol Lett 222:9-16.

Miranda KR, Dias MF, Guimarães PLS et al. (2008) Enterotoxigenic and nontoxigenic Bacteroides fragilis strains isolated in Brazil. Mem Inst Oswaldo Cruz 103:734-735.

Merino VR, Nakano V, Liu C et al. (2011) Quantitative detection of enterotoxigenic Bacteroides fragilis subtypes isolated from children with and without diarrhea. J Clin Microbiol 49:416-418.

Musso G, Gambino R, Cassander M (2011) Interactions between gut microbiota and host metabolism predisposing to obesity and diabetes. Annu Rev Med 63:361-380.

Nguyen TV, Van PL, Huy CL et al. (2005) Diarrhea caused by enterotoxigenic Bacteroides fragilis in children less than 5 years of age in Hanoi, Vietnam. Anaerobe 11:109-114.

Pantosti A, Malpeli M, WILKS M et al. (1997) Detection of enterotoxigenic Bacteroides fragilis by PCR. J Clin Microbiol 35:2482-2486.

Prindiville TP, Sheikh RA, Cohen SH et al. (2000) Bacteroides fragilis enterotoxin gene sequences in patients with inflammatory bowel disease. Emerg Infect Dis 6:171-174.

Sack RB, Albert MJ, Alam K et al. (1994) Isolations of enterotoxigenic Bacteroides fragilis from Bangladeshi children with diarrhea: a controlled study. J Clin Microbiol 32:960963. 
Shen Y, Giardino TML, Lawson GW et al. (2012) Outer membrane vesicles of a human commensal mediate immune regulation and disease protection. Cell Host Microbe 12:1-12.

Tong J, Liu C, Summanen P et al. (2011) Application of quantitative real-time PCR for rapid identification of Bacteroides fragilis group and related organisms in human wound samples. Anaerobe 17:64-68.

Toprak NU, Yagci A, Gulluoglu BM et al. (2006) A possible role of Bacteroides fragilis enterotoxin in the aetiology of colorectal cancer. Clin Microbiol Infect 12:782-786.
Tzianabos AO, Onderdonk AB, Smith RS et al. (1994) Structure-function relationships for polysaccharide-induced intra-abdominal abscesses. Infect Immun 62:3590-3593.

Wick EC, Sears CL (2010) Bacteroides spp. and diarrhea. Curr Opin Infect Dis 23:470-474.

Zitomersky NL, Coyne MJ, Comstock LE (2011) Longitudinal analysis of the prevalence, maintenance, and IgA response to species of the order Bacteroidales in the human gut. Infect Immun 79:2012-2020.

Associate Editor: Beatriz Ernestina Cabilio Guth

All the content of the journal, except where otherwise noted, is licensed under a Creative Commons License CC BY-NC. 